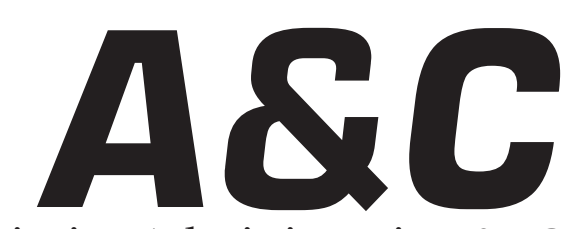

Revista de Direito Administrativo \& Constitucional

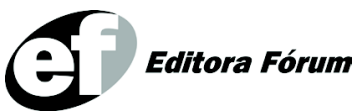

ISSN 1516-3210

A\&C R. de Dir. Administrativo e Constitucional Belo Horizonte ano 7 n. 29 p. $1-250$ jul./set. 2007 


\section{A\&C REVISTA DE DIREITO ADMINISTRATIVO E CONSTITUCIONAL}

IPDA

Instituto Paranaense

de Direito Administrativo

Direção Geral

Romeu Felipe Bacellar Filho

Direção Editorial

Paulo Roberto Ferreira Motta

Direção Executiva

Emerson Gabardo

Conselho de Redação

Edgar Chiuratto Guimarães

Adriana da Costa Ricardo Schier

Célio Heitor Guimarães

\section{Conselho Editorial}

Jorge Luís Salomoni - in memoriam (Argentina)

José Carlos Abraão (Brasil)

José Carlos Abraão (Brasil)
José Eduardo Martins Cardoso (Brasil)

José Luís Said (Argentina)

José Mario Serrate Paz (Uruguai)

Juan Pablo Cajarville Peruffo (Uruguai)

Juarez Freitas (Brasil)

Julio Rodolfo Comadira - in memoriam

(Argentina)

Luís Enrique Chase Plate (Paraguai)

Lúcia Valle Figueiredo (Brasil)

Manoel de Oliveira Franco Sobrinho

in memoriam - (Brasil)

Marçal Justen Filho (Brasil)

Marcelo Figueiredo (Brasil)

Márcio Cammarosano (Brasil)
Maria Cristina Cesar de Oliveira (Brasil)

Nelson Figueiredo (Brasil)

Odilon Borges Junior (Brasil)

Pascual Caiella (Argentina)

Paulo Eduardo Garrido Modesto (Brasil)

Paulo Henrique Blasi (Brasil)

Paulo Neves de Carvalho - in memoriam

(Brasil)

Paulo Ricardo Schier (Brasil)

Pedro Paulo de Almeida Dutra (Brasil)

Regina Maria Macedo Nery Ferrari (Brasil)

Rogério Gesta Leal (Brasil)

Rolando Pantoja Bauzá (Chile)

Sérgio Ferraz (Brasil)

Valmir Pontes Filho (Brasil)

Yara Stropa (Brasil)

Weida Zancaner (Brasil)

A246 A\&C Revista de Direito Administrativo e Constitucional. ano 3, n. 11, jan./mar. 2003. Belo Horizonte: Fórum, 2003.

Trimestral

ano 1, n.1, 1999 até ano 2, n.10, 2002 publicada pela Editora Juruá em Curitiba

ISSN 1516-3210

1. Direito Administrativo. 2. Direito Constitucional. I. Fórum.

CDD: 342 CDU: 33.342

C 2007 Editora Fórum Ltda.

Todos os direitos reservados. É proibida a reprodução total ou parcial, de qualquer forma ou por qualquer meio eletrônico ou mecânico, inclusive através de processos xerográficos, de fotocópias ou de gravação, sem permissão por escrito do possuidor dos direitos de cópias (Lei $n^{\circ}$ 9.610, de 19.02.1998).

Editora Fórum Ltda.

Av. Afonso Pena, 2770 - 15\% $16^{\circ}$ andar - Funcionários

CEP 30130-007 - Belo Horizonte/MG - Brasil

Tel.: 08007043737

Internet: www.editoraforum.com.br

e-mail: editoraforum@editoraforum.com.br
Editor responsável: Luís Cláudio Rodrigues Ferreira Coordenação editorial: Olga M. A. Sousa

Projeto gráfico e diagramação: Luis Alberto Pimenta

Revisora: Bárbara Christiane

Pesquisa jurídica: Fátima Ribeiro - OAB/MG 74868

Bibliotecária: Leila Aparecida Anastácio - CRB 2809/MG 6a região

Os conceitos e opiniões expressas nos trabalhos assinados são de responsabilidade exclusiva de seus autores.

Impressa no Brasil / Printed in Brazil

Distribuída em todo o Território Nacional 


\title{
Los fines del Derecho Público en México (La Supremacía del Derecho Público so- bre el Derecho Privado)
}

\author{
Lucinda Villarreal Corrales \\ Profesora de Derecho Administrativo de la Universidad Nacional Autónoma del México.
}

Palabras clave: Derecho público. Derecho privado. Ordenamiento jurídico mexicano. Derecho internacional. Derecho de la Cooperación Internacional.

1 La supremacía del derecho público sobre el derecho privado no ha llegado a su fin porque el Estado y el Derecho Público lejos de perder facultades las han visto acrecentadas, a tal grado que son omnipresentes en la vida total de los individuos. La primacía del derecho público sobre el derecho privado se funda en los fines que persigue, fines que resultan exorbitantes para el derecho privado; tales como la justicia, la seguridad pública y el desarrollo nacional.

2 El derecho público y el derecho privado. La doctrina afirma que los conceptos público y privado son temas clásicos vigentes desde la creación del derecho romano; ${ }^{1}$ que el concepto de público se asocia con el concepto de colectividad; que el hombre sólo puede vivir asociado a sus semejantes y para asegurar su supervivencia y el logro de sus fines ha creado un instrumento de orden social, el Derecho. El Derecho se identifica con el orden y el fenómeno jurídico aparece ligado fenómeno social, a la sociedad civil. ${ }^{2}$ Estado, Sociedad, Derecho y Orden son una unidad; el derecho existe donde hay una sociedad. ${ }^{3} \mathrm{El}$ derecho como regla de comportamiento no es un producto espontáneo e irreflexivo de un grupo informal, sino la creación, "artificial y consciente" de un grupo estructurado. Sólo el Derecho pone al hombre en relación con los demás. El derecho como norma, ordenamiento y relación. ${ }^{4}$ El derecho público y el derecho privado están interrelacionados; el derecho público ha ido creciendo, cada día tiene más presencia en la vida individual y social y no es posible deslindar un concepto de otro.

\footnotetext{
Ulpiano dice publicum ius est quod ad statum rei romanaespectat, privatum quod ad singularum utilitaten (el derecho público es aquel que se refiere a la República; el privado aquel que se refiere al interés de los particulares). D.I.1.1.2 citado por Margadant, Guillermo, Derecho Romano, 7. ed., México, esfinge, 1977, p. 102.

2 El concepto de sociedad civil, como conjunto de relaciones económicas y de vínculos sociales, es moderno. Lumia, Giuseppe, Principios de Teoría e ideología del Derecho, Madrid, Debate, 1982, p. 78.

Ibídem, p. 17.

4 Ibídem, p. 9-24.
}

A \& C R. de Dir. Administrativo e Constitucional, Belo Horizonte, ano 7, n. 29, p. 223-241, jul./set. 2007 
Lo público como un espacio de asociación y comunicación; ${ }^{5}$ lo público como sinónimo de lo estatal. El derecho administrativo la vía para el cumplimiento de los fines del Estado. La doctrina afirma que el derecho público y las instituciones fueron creados para el ordenamiento de la convivencia social. El Estado, gobierno y administración, como gestores del interés general, ideal político, que ha existido a lo largo de la historia. ${ }^{6}$ El Estado, la persona jurídica que protege, tramita o se encarga del interés colectivo.

El Estado se vale del derecho público para defender el interés general y evitar o limitar la propensión de los individuos al abuso y a la violencia, causa de grandes trastornos sociales. El Estado, el Derecho público y la administración pública para el cumplimiento de sus fines se legitiman por la política. ${ }^{7}$ El Estado a través del derecho público cumple con que demanda de la justicia distributiva ${ }^{8}$ que la actual sociedad demanda, asegura a los individuos y grupos humanos un mínimo nivel de existencia y de igualdad de oportunidades, al dirigir el desarrollo, la educación, la salud, la seguridad, la cultura.

El derecho público actúa como ordenador, regulador al servicio de la comunidad. ${ }^{9}$ La tarea esencial del Estado, su razón de existir es asegurar la justicia; la seguridad y bienestar públicos y administrar el patrimonio en ara del interés general. El derecho administrativo regula los intereses colectivos, conforma la organización del Estado; y el límite a su actuación lo impone la Constitución. El derecho administrativo responde a los intereses y necesidades colectivas, en tanto existan las necesidades públicas tendrá primacía el derecho público y la administración pública. En tanto exista el Estado como representante de la colectividad existirá el derecho público; Estado y Derecho público son solo uno.

3 El Estado de Derecho. El Estado mexicano somete todas sus acciones a normas fijas y conocidas de antemano; normas que permiten a cada individuo saber como usará la autoridad sus facultades coercitivas y este conocimiento rige el actuar de cada individuo. El derecho público fija las normas determinantes de las condiciones bajo las cuales pueden utilizarse los recursos disponibles; las normas

\footnotetext{
5 La sociedad esta en un proceso de comunicación, de entendimiento, de consenso.

6 Aristóteles, Tomas de Aquino y Moro ya demandaban para los individuos el ideal de una vida buena. Jürgen Habermas, Teoría y Praxis, Estudios de filosofía social, México, Rei, 1993, p. 54-63.

7 En México, los partidos políticos luchan en elecciones democráticas y pacíficas, por obtener el mando del poder ejecutivo, federal y estatal, convenciendo a los electores de la bondad de sus programas sociales, políticos, culturales y económicos.

8 La justicia ha asumido un carácter que depende más de apreciaciones que de reglas determinadas; basadas en las diferencias del caso, la diversidad de los hechos o de los sujetos. El Derecho como un objetivo que concuerda en la vía de la adjudicación de derechos, con la satisfacción de las necesidades y la no-discriminación de los intereses. Gianluigi Palombella, Filosofía del Derecho, Moderna y contemporáneas, Madrid, Tecnos, 1999, p. 319.

9 La Ley Federal de Responsabilidades de los Servidores Públicos DOF 31.12.82, asegura el cumplimiento de esta función de servicio.
} 
públicas no se dirigen a satisfacer las necesidades y deseos de ningún individuo en particular, atienden las necesidades de la gente en la medida en que se presentan y prevén estrategias de desarrollo a corto, mediano y largo plazo. Las leyes mexicanas indican como actuará el Estado en las diversas situaciones, como deben comportarse los individuos y se caracteriza por la ausencia de privilegios.

El Estado mexicano está en permanente transformación a través del consenso político; realiza grandes esfuerzos para mejorar su actitud de servicio, con la transparencia ${ }^{10}$ y publicidad obligatoria de los actos jurídicos; procedimientos administrativos claros; la revisión como único recurso de impugnación; la responsabilidad patrimonial de sus actos; la promoción de la sana competencia económica; la simplificación administrativa y el combate a la corrupción. Se somete a la supervisión de los órganos constitucionales autónomos y de control presupuestal; tiene la rectoría de la planeación para el desarrollo que comprende todas las acciones de la Federación y está en búsqueda del fortalecimiento de la seguridad pública, a través de la lucha permanente contra la delincuencia y el crimen organizado. El Estado mexicano, lejos de ver disminuidas sus facultades las ha visto acrecentadas y estas renovadas formas de acción afirman la primacía y la importancia del derecho público en México.

4 El Estado mexicano en su carácter de servidor público. La esencia del Estado mexicano es el servicio. En México son servidores públicos los individuos que desempeñan las funciones administrativa, judicial y legislativa. Todos los trabajadores del Estado son servidores públicos. La Constitución Política de los Estados Unidos Mexicanos en el artículo 108 dice que son servidores públicos los representantes de elección popular, los miembros del Poder Judicial Federal y del Poder Judicial del Distrito Federal, los funcionarios y empleados y toda persona que

\footnotetext{
${ }^{10}$ El Derecho de acceso a la información gubernamental esta en proceso de integrarse a la Constitución; al adicionar un segundo párrafo al a. $6^{\circ}$ de la misma, con siete fracciones que establecerá lo siguiente: Para el ejercicio del derecho de acceso a la información, la Federación, los Estados y el Distrito Federal, en el ámbito de sus respectivas competencias se regirán por los siguientes principios y bases: I. Toda la información en posesión de cualquier autoridad, entidad, órgano y organismo federal, estatal y municipal, es pública y sólo podrá ser reservada temporalmente por razones de interés público en los términos que fijen las leyes. En la interpretación de este derecho deberá prevalecer el principio de máxima publicidad. II. La información que se refiere a la vida privada y los datos personales será protegida en los términos y con las excepciones que fijen las leyes. III. Toda persona, sin necesidad de acreditar interés alguno o justificar u utilización, tendrá acceso gratuito a la información pública, a sus datos personales o a la rectificación de éstos. IV. Se establecerán mecanismos de acceso a la información y procedimientos de revisión expeditos. Estos procedimientos se sustanciarán ante órganos u organismos especializados e imparciales, y con autonomía operativa, de gestión y de decisión. V. Los sujetos obligados deberán preservar sus documentos en archivo administrativos actualizados y publicarán a través de los medios electrónicos disponibles, la información completa y actualizada sobre sus indicadores de gestión y el ejercicio de los recursos públicos. VI. Las leyes determinarán la manera en que los sujetos obligados, deberán hacer pública la información relativa a los recursos públicos que entreguen a personas físicas y morales. VII. La inobservancia a las disposiciones en materia de acceso a la información pública será sancionada en los términos que dispongan las leyes.
} 
desempeñe un empleo, cargo o comisión de cualquier naturaleza en la Administración Pública Federal o en el Distrito Federal y el del Instituto Federal Electoral, y serán responsables por los actos u omisiones en que incurran en el desempeño de sus respectivas funciones. ${ }^{11}$ La Ley Federal de Responsabilidades de los Servidores Públicos ${ }^{12}$ sanciona la conducta irregular de los mismos. Los tres poderes, el administrativo, el judicial y el legislativo están al servicio del pueblo mexicano.

5 Los órganos constitucionales autónomos. El ordenamiento interno del Estado mexicano se ha enriquecido con la creación de los órganos constitucionales autónomos; éstos son instituciones recientes, ${ }^{13}$ son órganos públicos con funciones específicas distintas a las que realizan los órganos de los poderes legislativo, administrativo y judicial. Sus funciones son de control, vigilancia y supervisión de la actuación de los poderes ya establecidos. Son instituciones al servicio de la colectividad.

Los órganos constitucionales autónomos son creados en forma directa por la Constitución, sus atribuciones son determinadas por la misma y cumplen una función específica dentro del Estado, y aunque no se encuentran subordinados a ningún poder, sus resoluciones son revisables de acuerdo con lo que establezca la Constitución; surgen por la necesidad de desarrollar funciones nuevas que por sus características no pueden llevar cabo los órganos ya establecidos; por motivos de seguridad pública, estabilidad social, certidumbre política, justicia social o conveniencia política.

En México son cuatro los órganos constitucionales autónomos: los tribunales agrarios, de jurisdicción federal, dirimen todos los problemas por limites de terrenos ejidales y comunales, cualquiera que sea el origen de éstos, se hallen pendientes o se susciten entre dos o más núcleos de población; así como los relacionados por la tenencia de la tierra de los ejidos y comunidades; el Banco Central o Banco de México, su objetivo prioritario es procurar la estabilidad del poder adquisitivo de la moneda nacional, fortaleciendo con ello la rectoría del desarrollo nacional que corresponde al Estado; el Instituto Federal Electoral realiza la función estatal de organizar las elecciones federales y el padrón electoral; fortalece el régimen de

\footnotetext{
${ }^{11}$ El Presidente de la República, durante el tiempo de su encargo, sólo podrá ser acusado por traición a la patria y delitos graves del orden común.

Los Gobernadores de los Estados, los Diputados a las Legislaturas Locales, los Magistrados de los Tribunales Superiores de Justicia Locales y, en su caso, los miembros de los Consejos de las Judicaturas Locales, serán responsables por violaciones a esta Constitución y a las leyes federales, así como por el manejo indebido de fondos y recursos federales.

Las Constituciones de los Estados de la República precisarán, en los mismos términos del primer párrafo de este artículo y para los efectos de sus responsabilidades, el carácter de servidores públicos de quienes desempeñen empleo, cargo o comisión en los Estados y en los Municipios.

12 DOF 31.12.1982, última reforma 13 de junio de 2003.

${ }^{13}$ Tribunales Agrarios fueron creados en 1992; El Banco de México es autónomo desde 1994; La Comisión Nacional de Derechos Humanos fue creada en 1990; el Instituto Federal Electoral 11 de octubre de 1990.
} 
partidos políticos, vela por la autenticidad y efectividad del sufragio; la Comisión Nacional de los Derechos Humanos, protege los derechos que ampara el orden jurídico mexicano. El los próximos meses se integraran a este grupo los órganos autónomos de información gubernamental y los órganos de coordinación del Sistema Nacional de Información Estadística y Geográfica; tal como lo disponen los recientemente reformados aa. $6^{\circ}$ y 26 constitucionales, que ordenan la creación de órganos con autonomía técnica y de gestión, personalidad jurídica y patrimonios propios para asegurar el derecho de toda persona a acceder a la información gubernamental, el primero y para normar y coordinar el Sistema nacional de Información Estadística y Geográfica, el segundo.

Los órganos constitucionales autónomos son públicos, y tienen como principal propósito resguardar los intereses de la colectividad y de los individuos en particular, gozan de una autonomía que los separa de las instancias ordinarias de decisión política: ${ }^{14} \mathrm{y}$ tienen un régimen temporal que trasciende el mandato sexenal del Ejecutivo en turno, lo que garantiza el cumplimiento de sus fines independientemente del grupo político en turno. ${ }^{15}$

Los organismos constitucionales autónomos son entes públicos creados para resguardar los derechos subjetivos de los ciudadanos en el ámbito político, social, económico y de derechos humanos; son entes jurídicos públicos al cuidado de los intereses de la colectividad y de los individuos en particular.

6 La transparencia de los actos jurídicos del Estado. La ley ordena que las decisiones públicas sean adoptadas y comunicadas con transparencia y establece los procedimientos administrativos correspondientes. ${ }^{16}$ La libertad de información y la publicidad de los procesos de las decisiones públicas además de ser obligatorias; fortalecen la seguridad jurídica; e inciden en la economía al aumentar la confianza de los inversionistas.

En este sentido y para el cumplimiento de estos fines, la últimas reformas al a. $6^{\circ}$ constitucional y la Ley Federal de Transparencia y acceso a la Información

\footnotetext{
14 Los órganos constitucionales autónomos realizan funciones auxiliares del Estado, funciones técnico-jurídicas, de vigilancia, de defensa, de justicia, de control, de certidumbre política.

${ }^{15}$ La Constitución establece que los magistrados electorales duran en su encargo 7 años a. 41, el Presidente de la Comisión de Derechos Humanos 5 y puede ser reelecto una sola vez a. 102; el Presidente magistrado agrario será nombrado por 3 años y podrá ser reelecto, los magistrados durarán en su encargo seis años. Si concluido dicho término fueren ratificados serán inamovibles; el gobernador del Banco de México durará seis años y el de Subgobernador será de ocho años. El periodo del Gobernador comenzará el primero de enero del cuarto año calendario del periodo correspondiente al Presidente de la República. Los periodos de los Subgobernadores serán escalonados, sucediéndose cada dos años e iniciándose el primero de enero del primer, tercer y quinto año del periodo del Ejecutivo Federal. Las personas que ocupen esos cargos podrán ser designadas miembros de la Junta de Gobierno más de una vez. aa. 38 y 40 Ley del Banco de México, DOF 23.12.1993, reformada por última vez el 31.12.2000.

${ }^{16}$ La Ley Federal de Transparencia y Acceso a la Información Pública Gubernamental DOF 11.06.2002 y la Ley Federal de Procedimiento Administrativo DOF 04.08.94.
} 
Pública Gubernamental, de orden público, con la finalidad de proveer lo necesario para garantizar el acceso de toda persona a la información en posesión de los Poderes de la Unión, los órganos constitucionales autónomos o con autonomía legal, y cualquier otra entidad federal.

7 El Procedimiento Administrativo. La Ley Federal del Procedimiento Administrativo garantiza la legalidad de los actos administrativos, al establecer el procedimiento para impugnar los actos de la administración federal a través del recurso de revisión. Sus disposiciones de orden e interés públicos, se aplican a los actos, procedimientos y resoluciones de la Administración Pública Federal centralizada, a los organismos descentralizados de la administración pública federal paraestatal respecto a sus actos de autoridad, a los servicios que el estado preste de manera exclusiva, y a los contratos que los particulares sólo puedan celebrar con el mismo, sin perjuicio de lo dispuesto en los Tratados Internacionales de los que México sea parte.

8 La Responsabilidad objetiva del Estado. La Constitución Política de los Estados Unidos Mexicanos recientemente incorporó en el segundo párrafo del a. 113, la responsabilidad objetiva del Estado, un derecho anhelado por los mexicanos durante mucho tiempo; con esta reforma el Estado es responsable por los daños que, con motivo de su actividad administrativa irregular, cause en los bienes o derechos de los particulares; está es objetiva y directa. Los particulares tienen derecho a una indemnización conforme a las bases, límites y procedimientos que establezcan las leyes.

La Ley Federal de Responsabilidad Patrimonial del Estado, ${ }^{17}$ reglamentaria del segundo párrafo del artículo 113, de orden público e interés general; fija las bases y procedimientos para reconocer el derecho a la indemnización a quienes, sin obligación jurídica de soportarlo, sufran daños en cualquiera de sus bienes y derechos como consecuencia de la actividad administrativa irregular del Estado. La responsabilidad extracontractual a cargo del Estado es objetiva y directa, y la indemnización deberá ajustarse a los términos y condiciones señalados en esta Ley y en las demás disposiciones legales a que la misma hace referencia.

La reforma constitucional que incorpora la responsabilidad objetiva del Estado y la Ley Federal de Responsabilidad Patrimonial del Estado reiteran que el derecho público garantiza el derecho de los particulares a ser indemnizados por los actos irregulares del Estado, que la interrelación entre el Estado y los particulares se encamina a ser equitativa, que las acciones del Estado son causa de responsabilidad; ${ }^{18}$ que el Estado, resguarda y respeta los derechos de los particulares frente a la administración pública. La Constitución y la ley de responsabilidad patrimonial son el gran marco que legitima las pretensiones de los particulares en

${ }^{17}$ DOF 31.12.2004.

A \& C R. de Dir. Administrativo e Constitucional, Belo Horizonte, ano 7, n. 29, p. 223-241, jul./set. 2007 
caso de proceder una indemnización o el resarcimiento de sus derechos debido a la actividad irregular de la administración.

9 La libre competencia. Las relaciones económicas privadas a través de las cuales los hombres proveen su sostenimiento o luchan por la posesión de los bienes o se organizan para devenir una fuerza económica detentadora de riqueza, también están protegidas por el Estado, por el derecho público, por medio de un complejo sistema de leyes económicas; una de ellas, por ejemplo, la que protege las reglas de la libre competencia que tiene como fin resguardar una economía basada en la propiedad y los contratos, que asegura que los intercambios no se obstaculicen. La competitividad económica está reconocida por el Estado a través de leyes e instituciones creadas para ese efecto. La Ley de Competencia ${ }^{19}$ protege el proceso de competencia y libre concurrencia, mediante la prevención y eliminación de monopolios, prácticas monopólicas y otras restricciones al funcionamiento eficiente de los mercados de bienes y servicios. Esta ley y muchas otras ${ }^{20}$ de igual importancia son disposiciones públicas que garantizan el quehacer económico privado en México. El Estado y el Derecho público se nos muestran claramente como ordenadores de la conducta económica.

10 La planeación en México. El Estado mexicano organiza el sistema de planeación democrática del desarrollo nacional para imprimir solidez, dinamismo y permanencia y equidad al crecimiento de la economía para la independencia y democratización política, social y cultural. La Constitución contiene los fines del proyecto nacional que determinan los objetivos de la planeación. La planeación es democrática, participan los diversos sectores sociales, recoge las aspiraciones y demandas sociales y las incorpora al Plan y los programas de desarrollo. Es responsabilidad del Ejecutivo Federal establecer los procedimientos de participación y consulta popular en el sistema de planeación; los criterios para la formulación, instrumentación, control y evaluación del plan y los programas de desarrollo; los órganos responsables del proceso de planeación y las bases para convenir con los gobiernos de las entidades federativas e inducir y concertar con los particulares las acciones a realizar para su elaboración y ejecución.

Lo datos del Sistema Nacional de Información estadística y Geográfica

\footnotetext{
18 ... [El fundamento jurídico formal de la obligatoriedad jurídica del ordenamiento del Estado consiste en la auto-obligación del propio Estado]... G. Jellinek, citado por Gianluigi Palombella, ob.cit. supra p. 108.

19 La ley Federal de Competencia Económica DOF 24.12.92, reformada por última vez el 26.01.2006.

${ }^{20}$ La Ley Aduanera, DOF 15.12.1995; Ley de Instituciones de Crédito, DOF 10.07.1990; Ley de Inversión Extranjera, DOF 27.12.1993; Ley de la Comisión Bancaria y de Valores, DOF 28.04.1995; Ley de la Propiedad Industrial, DOF 27.06.1991; Ley de Protección al Ahorro Bancario, DOF 19.01.1999; Ley de Protección al Comercio y Normas Extranjeras que Contravengan el Derecho Internacional, DOF 18.01.1999; Ley de Protección y Defensa al Usuario de Servicios Financieros, DOF 18.01.1999; Ley de Sociedades de Inversión, DOF 04.06.2001; Ley para el Desarrollo de la Competitividad de la Micro, Pequeña y Mediana Empresa, DOF 30.12.2002; y otras más.
}

A \& C R. de Dir. Administrativo e Constitucional, Belo Horizonte, ano 7, n. 29, p. 223-241, jul./set. 2007 
son oficiales, ${ }^{21}$ la normatividad y coordinación de dicho sistema está a cargo de un órgano autónomo. ${ }^{22}$

El Presidente de la República remite el Plan al Congreso de la Unión para su examen y opinión. El Plan Nacional de Desarrollo se elabora, aprueba y publica dentro de un plazo de seis meses contados a partir de la fecha en que toma posesión el Presidente de la República, y su vigencia no excede del período constitucional que le corresponda, aunque puede contener consideraciones y proyecciones de más largo plazo.

El Plan Nacional de Desarrollo precisa los objetivos nacionales, estrategia y prioridades del desarrollo integral y sustentable del país, contiene previsiones sobre los recursos que serán asignados a tales fines; determina los instrumentos y responsables de su ejecución, establece los lineamientos de política de carácter global, sectorial y regional; sus previsiones se refieren al conjunto de la actividad económica y social, tomando siempre en cuenta las variables ambientales que se relacionen a éstas y rige el contenido de los programas que se generan en el sistema nacional de planeación democrática. La categoría de Plan queda reservada al Plan Nacional de Desarrollo. ${ }^{23}$

En México, el Estado somete toda la actividad económica a una planeación, a un plan sexenal primordialmente. ${ }^{24}$ La Ley de Planeación es de orden público e interés social, establece las normas y principios de la Planeación Nacional del Desarrollo; encauza las actividades de la administración Pública Federal; sienta las bases para que el Ejecutivo Federal coordine sus actividades de planeación con las entidades federativas y los diversos grupos sociales así como de los pueblos y comunidades indígenas; y particulares que contribuyen a alcanzar los objetivos y prioridades del plan y los programas. La planeación es un medio para el eficaz desempeño de la responsabilidad del Estado sobre el desarrollo integral y sustentable del país y tiende a la consecución de los fines y objetivos políticos, sociales, culturales y económicos contenidos en la Constitución Política de los Estados Unidos Mexicanos.

$11 \mathrm{El}$ control presupuestal. Los recursos públicos como facultad unigénica de Estado. La imprescindible facultad del Estado para recibir los recursos necesarios para atender las necesidades públicas está establecida en el IV párrafo del a. 31 de la Constitución. ${ }^{25}$ La Ley de Ingresos de la Federación establece como formas de ingreso los impuestos, las contribuciones a mejoras, los derechos, los

\footnotetext{
21 Para la Federación, entidades federativas y Distrito Federal y municipios, los datos contenidos en el sistema son de uso obligatorio en los términos que establézcanla ley.

22 A. 26 constitucional DOF 7 de abril de 2006.

${ }^{23}$ Artículos $3^{\circ}, 4^{\circ}, 5^{\circ}$ y 21 de la Ley de Planeación.

${ }^{24}$ La Ley de Planeación DOF 05.01.1983, prevé que el al iniciar su gestión el Presidente de México a más tardar en el mes de mayo del primer año de su mandato presente su Plan Nacional de Desarrollo al que se sujetaran todas las acciones de la Federación, los gobiernos estatales y municipales.
} 
aprovechamientos, los ingresos de organismos y empresas; las aportaciones de seguridad social e ingresos derivados de financiamientos o empréstitos; pero estos últimos, sólo para proyectos de inversión o actividades productivas, como lo establece el a. 4 fracción V de la Ley General de Deuda Pública ${ }^{26}$ que faculta al Ejecutivo Federal a través de la Secretaría de Hacienda para contratar y manejar la deuda pública del Gobierno Federal y otorgar la garantía del mismo para la realización de operaciones crediticias que se celebren con organismos internacionales de los cuales o de países extranjeros, siempre que los créditos estén destinados a la realización de proyectos de inversión o actividades productivas que estén acordes con las políticas de desarrollo económico y social aprobadas por el Ejecutivo y que generen los recursos suficientes para el pago del crédito y tengan las garantías adecuadas.

12 El control del endeudamiento gubernamental en México. El Congreso de la Unión autoriza anualmente los montos del endeudamiento directo neto interno y externo necesarios para el financiamiento del Gobierno Federal y las entidades del sector público federal incluidas en la Ley de Ingresos la Federación, así como del Departamento del Distrito Federal. El Ejecutivo Federal informa al Congreso de la Unión del estado de la deuda, al rendir la cuenta pública anual y al remitir el proyecto de ingresos, asimismo informa trimestralmente de los movimientos de la misma, dentro de los cuarenta y cinco días siguientes al vencimiento del trimestre respectivo.

La Ley de Ingresos de la Federación para el Ejercicio Fiscal de 2007 en el artículo 2o. autorizó al Ejecutivo Federal, por conducto de la Secretaría de Hacienda y Crédito Público, para contratar y ejercer créditos, empréstitos y otras formas del ejercicio del crédito público, incluso mediante la emisión de valores, en los términos de la Ley General de Deuda Pública y para el financiamiento del Presupuesto de Egresos de la Federación para el Ejercicio Fiscal 2007, por un monto de endeudamiento neto interno hasta por 240 mil millones de pesos. Asimismo, podrá contratar endeudamiento interno adicional al autorizado, siempre que se obtenga una disminución de la deuda pública externa por un monto equivalente al del endeudamiento interno neto adicional asumido.

El Ejecutivo Federal fue autorizado para contratar créditos o emitir valores en el exterior con el objeto de canjear o refinanciar obligaciones del Sector Público Federal a efecto de obtener un monto de desendeudamiento neto externo de al menos 500 millones de dólares de los Estados Unidos de América. El cómputo de lo anterior se realizará, en una sola ocasión, el último día hábil bancario del

\footnotetext{
25 Artículo 31. Son obligaciones de los mexicanos:... IV. Contribuir para los gastos públicos, así de la Federación, como del Distrito Federal o del Estado y Municipio en que residan, de la manera proporcional y equitativa que dispongan las leyes.

26 DOF 31.12.76 reformada por última vez el 21.12.1995.
}

A \& C R. de Dir. Administrativo e Constitucional, Belo Horizonte, ano 7, n. 29, p. 223-241, jul./set. 2007 
ejercicio fiscal de 2007 considerando el tipo de cambio para solventar obligaciones denominadas en moneda extranjera pagaderas en la República Mexicana que publique el Banco de México en el Diario Oficial de la Federación, así como la equivalencia del peso mexicano con otras monedas que dé a conocer el propio Banco de México, en todos los casos en la fecha en que se hubieren realizado las operaciones correspondientes.

También se autoriza al Ejecutivo Federal para que, a través de la propia Secretaría de Hacienda y Crédito Público, emita valores en moneda nacional y contrate empréstitos para canje o refinanciamiento de obligaciones del Erario Federal, en los términos de la Ley General de Deuda Pública. Asimismo, el Ejecutivo Federal queda autorizado para contratar créditos o emitir valores en el exterior con el objeto de canjear o refinanciar endeudamiento externo.

El Ejecutivo Federal quedó autorizado, en caso de que así se requiera, para emitir en el mercado nacional, en el ejercicio fiscal de 2007, valores u otros instrumentos indizados al tipo de cambio del peso mexicano respecto de monedas del exterior, siempre que el saldo total de los mismos durante el citado ejercicio no exceda del 10 por ciento del saldo promedio de la deuda pública interna registrada en dicho ejercicio y que, adicionalmente, estos valores o instrumentos sean emitidos a un plazo de vencimiento no menor a 365 días.

Las operaciones a las que se refieren el segundo y tercer párrafos de este artículo no deberán implicar endeudamiento neto adicional al autorizado para 2007.

Del ejercicio de las facultades a que se refiere este artículo, el Ejecutivo Federal dará cuenta trimestralmente al Congreso de la Unión, por conducto de la Secretaría de Hacienda y Crédito Público, dentro de los 30 días siguientes al trimestre vencido, especificando las características de las operaciones realizadas. En caso de que la fecha límite para informar al Congreso de la Unión sea un día inhábil la misma se recorrerá hasta el siguiente día hábil.

El Ejecutivo Federal también informará trimestralmente al Congreso de la Unión en lo referente a aquellos pasivos contingentes que se hubieran asumido con la garantía del Gobierno Federal durante el ejercicio fiscal de 2007, incluyendo los avales distintos de los proyectos de inversión productiva de largo plazo otorgados.

13 La seguridad pública y la seguridad nacional. La justicia penal o conmutativa, que demanda una acción correctiva, es monopolio del Estado, atiende al hecho y al daño; con la reparación o liberación de responsabilidad, tiene también como fin preservar el bienestar colectivo. En México en los últimos años se ha legislado para preservar la seguridad pública y combatir la delincuencia organizada que ha transpuesto las fronteras nacionales, que se ha transnacionalizado y tiene su sede en otros países. Nuestro país enfrenta enérgicamente el problema de delincuencia organizada nacional y transnacional a través de disposiciones 
públicas federales que contienen los compromisos de cooperación internacional penal firmados por el Ejecutivo federal y ratificados por el Senado.

En el orden social, la simbiosis derecho público-derecho privado, está presente en todas las actividades, no existe actividad privada fuera del orden establecido por las disposiciones públicas. El derecho público, omnipresente, en las actividades colectivas e individuales. Lo público orienta y resguarda la actividad individual, marca el rumbo y le da sentido a lo privado dentro del objetivo nacional. El particular puede realizar cualquier actividad dentro del Estado de derecho.

El Estado mexicano tutela la seguridad nacional, el artículo 29 constitucional establece que en los casos de invasión, perturbación grave de la paz pública, o de cualquier otro que ponga a la sociedad en grave peligro o conflicto, solamente el Presidente de los Estados Unidos Mexicanos, de acuerdo con los Titulares de las Secretarías de Estado, los Departamentos Administrativos y la Procuraduría General de la República y con aprobación del Congreso de la Unión, y, en los recesos de éste, de la Comisión Permanente, puede suspender en todo el país o en lugar determinado las garantías que fuesen obstáculo para hacer frente, rápida y fácilmente a la situación; pero debe hacerlo por un tiempo limitado, por medio de prevenciones generales y sin que la suspensión se contraiga a determinado individuo. Si la suspensión tuviese lugar hallándose el Congreso reunido, éste concederá las autorizaciones que estime necesarias para que el Ejecutivo haga frente a la situación, pero si se verificase en tiempo de receso, se convocará sin demora al Congreso para que las acuerde.

14 La unidad de la legislación mexicana. En México todas las leyes están sujetas a la Constitución y todas las actividades de la administración pública al Plan Nacional de Desarrollo; los ingresos, a la Ley de Ingresos de la Federación, que es anual y los gastos, al Presupuesto de Egresos de Egresos de la Federación, que también es anual. La actividad pública está constreñida a estas disposiciones. Todas las actividades de la Federación están previstas en el Plan y los programas de desarrollo; todas las leyes están encaminadas a cumplirlos y la constitución es el programa de acción a largo plazo.

15 Las facultades del Estado. La Constitución confiere al Estado la gran misión del desarrollo nacional, de la seguridad pública y de la preservación de la soberanía, misión que sólo puede lograr a través del Derecho público.

$16 \mathrm{El}$ orden público. La doctrina establece que la libertad individual y la libertad social están unidas a la idea de res publica (república o cosa), a la convivencia de los individuos. El orden público se justifica a partir de un pacto ideal entre individuos libres e iguales que convienen un orden que hace posible la vida social. El reconocimiento de derechos en ese pacto, se manifiesta como una distribución de poder entre individuos e instituciones, los poderes de las personas 
restringen los poderes de las instituciones. En México las garantías individuales y las garantías sociales marcan un coto a la actuación de los entes públicos. Sin embargo, la convivencia social a veces genera una confrontación entre los derechos individuales y sociales; el bien general exige que éstos se limiten para fines concretos de seguridad pública; de medio ambiente; de salud pública, de urbanismo o económicos, entre otros.

17 Los objetivos nacionales. El derecho tiene como fines supremos y primordiales primero la justicia, lo justo como lo que está "conforme a aquellos criterios ideales que deben presidir la buena dirección y el ordenado desarrollo de la cosa pública"; ${ }^{27}$ después el interés social, el bien de la colectividad o el bienestar general y por último la seguridad pública. Se afirma que derecho y colectividad tienen un origen simultáneo, nacieron al mismo tiempo. El Derecho público en México, por mandato constitucional, está al servicio del interés general. Abraham Lincoln ${ }^{28}$ dijo que el Estado debe hacer sólo aquello que el particular a pesar e todos sus esfuerzos no ha podido hacer. El particular ha delegado en el Estado el objetivo nacional, que rebasa sus capacidades; a delegado al Estado la visión de la Nación, ha delegado al Estado el cumplimiento de los ideales nacionales plasmados en la Constitución Política de los Estados Unidos Mexicanos.

El Estado, las instituciones, el derecho público en México son los responsables del cumplimiento de los objetivos nacionales y del desarrollo del país que promueve el desarrollo individual de los mexicanos. Los poderes, las instituciones, las empresas privadas tanto nacionales como extranjeras y los particulares participan con el Estado en el gran esfuerzo el desarrollo nacional. El derecho público, el gobierno, las instituciones están dedicados a preservar el Estado de derecho y satisfacer el bien común, a crear el estado de seguridad que los individuos demandan para su desarrollo. El derecho privado no tiene esa finalidad, no persigue el fin supremo del interés general.

El Estado, con el derecho público, es el responsable del bienestar de las poblaciones. El Estado en el cumplimento de sus fines se alza más allá de todo egoísmo particular para trabajar para el logro del bien general.

La administración pública y el derecho administrativo tienen un papel fundamental en la vida de los individuos. Las disposiciones administrativas influyen en todos y cada uno de los miembros de una sociedad. El derecho público atiende todos los aspectos de la vida social: salud, educación, comunicaciones, transporte, seguridad, estabilidad económica.

\footnotetext{
${ }^{27}$ Lumia, ob.cit. p. 113.

281860.
}

A \& C R. de Dir. Administrativo e Constitucional, Belo Horizonte, ano 7, n. 29, p. 223-241, jul./set. 2007 
18 El ordenamiento jurídico mexicano como estructura. Las normas jurídicas mexicanas forman un sistema coherente y perfectible. En el ordenamiento jurídico mexicano, en el nivel más elevado se colocan las normas constitucionales. La Constitución es la fuente superior de producción del Derecho.

El hecho de que el ordenamiento jurídico mexicano esté constituido por un conjunto de normas que derivan su validez de una única norma fundamental, la Constitución Política de los Estados Unidos Mexicanos no excluye la existencia de una pluralidad de ordenamientos jurídicos que también son ley Suprema de toda la Unión, los tratados internacionales. La dinámica del Derecho mexicano refleja tanto la idiosincrasia, requerimientos y objetivos de la sociedad mexicana; como los objetivos y anhelos de la sociedad internacional. ${ }^{29}$ Las normas internacionales penetran el derecho nacional, y nos hermanan con las sociedades del mundo que avanza hacia el ideal de la sociedad mundial.

El derecho internacional se incorpora a la legislación mexicana por los convenios ratificados por el Senado, estos compromisos nos enriquecen, rompen barreras de comunicación, trascienden nuestras fronteras y nos acercan a otros países. El Estado mexicano al convenir internacionalmente no sólo fortalece nuestra soberanía sino que colabora a la integración e la sociedad mundial. ${ }^{30}$

Los ordenamientos jurídicos internacionales y de Derecho Comunitario son supra ordenamientos que cambian las legislaciones nacionales. La fuerza del Derecho Internacional reside en que tiene que ser respetado por los nuevos Estados cuando se han manifestado en ese sentido, y aún cuando se han manifestado en sentido contrario. El Derecho comunitario, acuerdos estipulados entre los Estados, se vierte en la legislación pública de las naciones de la comunidad, homologando con ese acto, Estados y legislaciones muy diferentes entre si, pero vinculadas por una legislación superior que es el derecho comunitario o el derecho de la Unión, que crea interrelaciones permanentes de superación, cooperación y protección colectiva. La legislación mexicana también es receptáculo de la legislación de la comunidad europea con base en los convenios pactados.

19 México y los tratados de libre comercio. A la legislación mexicana que regula múltiples actividades económicas como el comercio, las importaciones y exportaciones; la inversión, nacional y extranjera; el sistema financiero, bancos y, aseguradoras; el sistema aduanero; ${ }^{31}$ se le suman las disposiciones y estrategias que comprenden los tratados de libre comercio. El primero fue el Tratado de Libre Comercio de América del Norte, vigente desde el $1^{\circ}$ de enero de 1994, con prevenciones económicas programáticas hasta el año 2019; es un contrato que contiene un ambicioso programa de inversión y liberación comercial; ${ }^{32}$ al que siguieron, con

29 La Organización de la Naciones Unidas y demás organizaciones internacionales.

${ }^{30}$ Son cientos los convenios en todas las áreas del conocimiento.

A \& C R. de Dir. Administrativo e Constitucional, Belo Horizonte, ano 7, n. 29, p. 223-241, jul./set. 2007 
la misma estructura, ${ }^{33}$ tratados de libre comercio con otros países de América, Europa, Medio Oriente y Asia. ${ }^{34}$ El Tratado con la Unión Europea llamado Acuerdo de Asociación Económica, Concertación Política y Cooperación contiene importantes compromisos que trascienden lo económico, como la llamada cláusula democrática ${ }^{35}$ sin embargo; tenemos que aclarar que la Constitución Política es el programa de acción más importante de nuestra Nación. Estos tratados de comercio representan un importante programa de integración económica, es visionario y nos integrará cada día más con nuestros países hermanos. El tiempo mostrará las bondades de esta estrategia comercial que comprende hasta ahora un mercado de más de 900 millones de personas.

El tratado de Libre Comercio de América del Norte ha sido la pauta de la transformación del país, en los trece años de vigencia, nuestro país está en vías de una modernización integral, no en la medida de lo esperado, pero los resultados han sido benéficos para el país.

Los tratados de libre comercio y los convenios internacionales firmados y ratificados por el Senado, en los últimos años, han propiciado la reforma total de nuestro sistema jurídico, de las 247 leyes federales más del $90 \%$ son o leyes reformadas o leyes nuevas.

20 La integración, la mundialización y la cooperación internacional. Es innegable que existe un ordenamiento mundial e instituciones internacionales reconocidas. La sociedad internacional está conformada por más de 200 Estados vinculados por acuerdos internacionales de toda índole. El Estado mexicano se ha comprometido en muchos instrumentos internacionales y la legislación se ha enriquecido al armonizarse con los tratados de los que somos Parte. Todas las disposiciones de la normatividad internacional ratificada se han integrado a la legislación nacional; han penetrado nuestro sistema jurídico y son Ley Suprema de toda la Unión. ${ }^{36}$

\footnotetext{
31 Ley Aduanera, DOF 15.12.95; Ley de Comercio Exterior, DOF 27.07.1993; Ley de Concursos Mercantiles, DOF 12.05.2000; Ley de Inversión Extranjera, DOF 27.12.1993; Ley Federal sobre Metrología y Normalización, DOF 01.07.1992; y otras.

32 Abrió a la inversión extranjera temas tan fundamentales como la obra pública y los contratos de suministro.

33 Todos los tratados de libre comercio se basan en los principios del GATT, desde 1995 administrado por la Organización Mundial de comercio OMC.

34 Con Chile, $1^{\circ}$ de agosto de 1999; con Venezuela y Colombia (G-3), $1^{\circ}$ de enero de 1995; con Costa Rica, $1^{\circ}$ de enero de 1995; con Bolivia, $1^{\circ}$ de enero de 1995; con Nicaragua, $1^{\circ}$ de julio de 1998; con Honduras, El Salvador y Guatemala(Triángulo del Norte), 15 de marzo de 2001; con la República Oriental del Uruguay, 15 de noviembre del 2003; con la Unión Europea, $1^{\circ}$ de julio de 2000; con Asociación Europea de Libre Comercio, $1^{\circ}$ de julio de 2001; con Israel, $1^{\circ}$ de junio de 2000; con Japón, 31 marzo 2005.

35 En los Principios Generales se establece que es fundamento e inspira las políticas internas e internacionales de las Partes y constituye un elemento esencial del Acuerdo, el respeto a los principios democráticos y a los derechos humanos fundamentales, tal como se enuncian en la Declaración Universal de los Derechos Humanos.
} 
Vivimos una época de integración, de mundialización, de expansión, liberalización, de cooperación; en todos los ámbitos; económicos, políticos, culturales, ideológicos. Esta época, se caracteriza por el incremento de la participación de la inversión de las empresas privadas nacionales y extranjeras en las economías nacionales; ustedes pensaran y dirán, esa participación siempre ha existido; es cierto, la diferencia es que ahora en México forma parte de un plan nacional; está encausada al crecimiento nacional y es fuente de empleo.

El sistema jurídico nacional se ha enriquecido al adoptar instituciones jurídicas que han sido benéficas en otros países; al incorporar disposiciones nacidas de convenios bilaterales y multilaterales. Los Convenios nos obligan en muy variados temas como los derechos humanos, narcotráfico, protección del medio ambiente, salud, educación, medios de comunicación, transportes; presentan problemas relacionados con la sociedad nacional y mundial; y nos integran a organizaciones económicas, políticas y culturales. La administración pública mexicana en sus tres niveles jurisdiccionales federal, estatal y municipal atiende los compromisos internacionales.

El derecho público es un principio de orden sobre el territorio donde ejerce su jurisdicción. El derecho internacional es un principio de orden sobre el mundo. Los convenios interrelacionan naciones, culturas que comparten ideales y propósitos comunes; las ideas se propagan de un país a otro y a los Estados nos identifican los propósitos y necesidades semejantes. El sistema jurídico público mexicano se está armonizando al sistema jurídico internacional con propósitos de desarrollo económicos, culturales, políticos, que promueven la convivencia pacífica. ${ }^{37}$ Lo que ahora llamamos globalización para nosotros solo es un movimiento incluyente de ideas que siempre ha existido.

La revolución informática basada en la conquista de la electrónica empequeñece al mundo; las comunicaciones muestran una capacidad excepcional de informar, culturizar con paquetes de información, entretenimientos e ideas, de carácter instantáneo. Las consecuencias de la mundialización cultural, de este intercambio de valores, ideas, modelos, sistemas, de otras realidades es todavía un terreno desconocido, inexplorado; pero seguramente positivo para la humanidad.

Los convenios nos encaminan hacia un nuevo derecho el derecho de la

\footnotetext{
${ }^{36}$ A. 133 Constitucional. "Esta Constitución, las leyes del Congreso de la unión que emanen de ella y todos los tratados que estén de acuerdo con la misma, celebrados y que se celebren por el Presidente de la república, con aprobación del Senado, serán la Ley Suprema de Toda la unión. Los jueces de cada Estado se arreglarán a dicha Constitución, leyes y tratados, a pesar de las disposiciones en contrario que pueda haber en las Constituciones o leyes de los Estados".

${ }^{37}$ Los principios que rigen nuestras relaciones con los otros pueblos del mundo están asentados en la Fracción X del artículo 89 constitucional... "la autodeterminación de los pueblos, la no intervención; la solución pacífica de controversias; la proscripción de la amenaza o el uso de la fuerza en las relaciones internacionales; la igualdad jurídica de los Estados; la cooperación internacional para el desarrollo; y la lucha por la paz y la seguridad internacionales".
}

A \& C R. de Dir. Administrativo e Constitucional, Belo Horizonte, ano 7, n. 29, p. 223-241, jul./set. 2007 
Cooperación Internacional. Este gran proyecto de integración mundial, está encomendado al Estado, al derecho público, no puede ser tarea del derecho privado, pero los particulares, las empresas y los individuos pueden participar a través del derecho administrativo.

21 El derecho público ċha perdido su supremacía? o ¿̇en qué radica la primacía del derecho público sobre el derecho privado? Nosotros afirmamos, que ahora más que nunca esta patente la importancia del derecho público, derecho encaminado al bienestar social y que el derecho privado se desarrolla y prospera en el marco de las disposiciones públicas; que el derecho privado como vínculo entre las partes que nace de un acuerdo o intercambio, es preservado por las disposiciones públicas, que garantizan la armonía entre los particulares que contribuyen con su acción a la convivencia social; que la actividad privada, con fines de beneficio o enriquecimiento se realiza en el marco del derecho y las instituciones públicas, por leyes financieras y comerciales públicas; que el derecho público provee a las personas físicas o morales, y a todos los agentes económicos; de las instituciones que requiere para desarrollarse, e influir en la elevación del nivel de vida de la sociedad. El derecho privado requiere de leyes que den certeza, que sean justas y se adapten a las cambiantes circunstancias nacionales e internacionales y éstas no son creadas por los particulares, sino por el Estado.

Es cierto que el gobierno alienta el incremento de la participación privada nacional y extranjera, pero esta participación debe contribuir al desarrollo nacional. Ante esta explosión de la actividad económica privada, parecería que el Estado y derecho público se retiran para dejar que los particulares tomen las riendas de la educación, la salud, las comunicaciones, los bancos, las aseguradoras y la economía en general; esto sólo es una apariencia; porque en México por mandato constitucional la rectoría económica está en manos del Estado. La liberalización de la actividad de los particulares es producto de una legislación pública que tiene como innegable propósito el interés general. La administración pública y el derecho administrativo no abandonan su liderazgo en el desarrollo, lo propician y fortalecen al incentivar la participación en el desarrollo de otros sectores económicos.

La desregulación administrativa en México, no quiere decir que el derecho público se retira del quehacer público y lejos de significar un abandono de sus fines, es una política pública que incentiva la participación de los particulares en las actividades económicas, es una estrategia del Estado para incrementar la participación de los agentes privados en el desarrollo nacional, a través de una simplificación administrativa, que disminuye el burocratismo y la corrupción que entorpecen, limitan e inhiben la participación privada.

El derecho público no se retira, no pierde preeminencia, su presencia, de acuerdo con la Constitución, es ahora de dirección; de aglutinador de esfuerzos, 
para un plan más ambicioso, un plan de acción más amplio, el del desarrollo nacional. La des-burocratización de la administración permite que a través de normas públicas más accesibles, más transparentes; se evite la corrupción y que los agentes privados nacionales o extranjeros, colaboren en un clima de confianza en todos los sectores económicos.

La administración se fortalece, el Estado ya no está solo en el esfuerzo nacional de desarrollo. La esencia de su rectoría es sumar esfuerzos, dar oportunidad a otros sectores; $;^{38}$ alentar al capital para que se quede en México; incentivar a los extranjeros para que con sus capitales y en una libre competencia contribuyan al desarrollo nacional. Lo que tenemos en México es una estrategia de crecimiento, corto, mediano y largo plazo, protegida por el derecho público y las instituciones, que trasciende los cambios de poder, los sexenios. El desarrollo nacional es una estrategia, un compromiso que no cambiará independientemente del Ejecutivo en turno.

La constitución y un vasto sistema jurídico, invisten al Estado mexicano, al gobierno de amplias facultades para dirigir al país y conducirlo, dentro del marco de la legalidad, a un estado de bienestar irreversible. Esta tarea aun no ha cumplido, este mandato, razón de existencia del derecho público aun está vigente. La Constitución ha erigido al Estado como rector del desarrollo nacional; ${ }^{39}$ pero también ha ordenado que a este desarrollo concurran todos los sectores, ${ }^{40}$ con sus ideas, con su trabajo, con sus capitales. El desarrollo nacional es el gran objetivo. La administración pública a través del cumplimiento del Plan Nacional de Desarrollo impulsa el crecimiento equitativo de la sociedad mexicana con la participación de los otros sectores sociales nacionales y extranjeros. El derecho público no ha perdido su primacía y el Estado no ha abandonado su papel de rector de la economía, sino que lo ha fortalecido con la participación conjunta de otros sectores.

Esta gran misión de la que el Estado es rector, no la puede lograr el derecho privado. La desregulación, la privatización, la simplificación administrativa, la transparencia, la desmonopolización, la liberalización administrativa, la descentralización son estrategias de gobierno, no significan un abandono de los fines

\footnotetext{
38 El sector privado y el sector social.

${ }^{39}$ A. 25 Constitucional. Corresponde al Estado la rectoría del desarrollo nacional para garantizar que éste sea integral y sustentable, que fortalezca la soberanía de la Nación y su régimen democrático y que, mediante el fomento del crecimiento económico y el empleo y una más justa distribución del ingreso y la riqueza, permita el pleno ejercicio de la libertad y la dignidad de los individuos, grupos y clases sociales, cuya seguridad protege esta Constitución.

El Estado planeará, conducirá, coordinará y orientará la actividad económica nacional, y llevará al cabo la regulación y fomento de las actividades que demande I interés general en el marco de las libertades que otorga esta Constitución..

40 A. 25 Constitucional... Al desarrollo económico nacional concurrirán, con responsabilidad social, el sector público, el sector social y el sector privado, sin menoscabo de otras formas de actividad económica que contribuyan al desarrollo de la Nación...
} 
del derecho público, de la administración pública, o del derecho administrativo. El Estado no está abandonando sus tareas primordiales, el desarrollo nacional, el resguardo de la seguridad pública, la elevación del nivel de vida de los ciudadanos o la creación un estado de bienestar para todos. El Estado invita a colaborar en la gran tarea del quehacer nacional a todos los sectores nacionales y aun extranjeros.

Estas tendencias significan, que el gobierno como rector del desarrollo nacional, necesita de la colaboración de todos, que el Estado moderno, no tiene el monopolio del desarrollo, que en el desarrollo debemos contribuir todos. Lo que el Estado si tiene es el monopolio de la dirección, de la rectoría de ese desarrollo. Esta nueva perspectiva demanda, que el gobierno, otrora único responsable del desarrollo, con gran visión, participe dirigiendo a los demás sectores para optimizar el cumplimiento de los fines colectivos a través de las políticas de derecho público.

La supremacía del derecho público subyace dentro del Estado, dentro de los gobiernos, forma parte de su esencia; el gobierno para todos dentro de un plan nacional de bienestar, es la condición sine qua non para su existencia. El derecho público siempre ha existido, por lo menos como dice la doctrina desde que existe el sentimiento aglutinador de colectividad, porque sólo él ha garantizado la sobre vivencia de la misma. El derecho público tiene preeminencia sobre el derecho privado, como afirma la doctrina, por los fines que persigue, lo colectivo; la seguridad; lo justo; algunos llegan a afirmar que sólo existe un derecho, el derecho público, que el derecho público subsume el llamado derecho privado; que su incita primacía reside en sus fines de interés general.

Es cierto que los particulares, cuando establecen las cláusulas en un contrato, cuando hacen su testamento, cuando ejecutan una compra venta, crean derecho al establecer reglas privadas que finalmente también son reglas de convivencia; pero también es cierto, que sólo el Estado y el Derecho público garantizan el ideal de libertad tan necesario para las relaciones intersubjetivas, o el ideal de justicia para la prevalencia de los derechos. El individuo y la colectividad existen y se interrelacionan dentro de los márgenes que garantiza el derecho publico. Todos los movimientos de los particulares y de la colectividad están regidos por el derecho público.

El derecho público esta muy lejos de haber cumplido con su finalidad, no se puede decir que ha llegado a su fin, o que ha perdido su primacía, porque otros sectores de una nación participen activamente en el desarrollo de un país; el derecho publico une grupos en otro tiempo dispersos, es el catalizador de esfuerzos que ahora trabajaran al unísono para un mismo fin, el estado de bienestar, la elevación del nivel de vida de los ciudadanos, el desarrollo y con ello el fortalecimiento de la Nación. El derecho público se ha fortalecido con las nuevas políticas 
administrativas mencionadas.

El Estado, por mandato constitucional y a través del derecho público, es el garante de los derechos humanos, de las relaciones comerciales, de la seguridad pública, de la educación, de la salud, de las comunicaciones, de las finanzas, entre otros muchos aspectos de convivencia igual de importantes. El Estado, a través del derecho público, es en México por mandato constitucional el rector del desarrollo nacional y el responsable de la seguridad pública.

Informação bibliográfica deste texto, conforme a NBR 6023:2002 da Associação Brasileira de Normas Técnicas (ABNT):

VILLARREAL CORRALES, Lucinda. Los fines del Derecho Público en México: (La Supremacía del Derecho Público sobre el Derecho Privado). A\&C Revista de Direito Administrativo e Constitucional, Belo Horizonte, ano 7, n. 29, p. 223-241, jul./set. 2007.

A \& C R. de Dir. Administrativo e Constitucional, Belo Horizonte, ano 7, n. 29, p. 223-241, jul./set. 2007 